\title{
Uma Visita a Museu e a Possibilidade de Inclusão de Surdos
}

\section{A Visit to the Museum and the Possibility of Inclusion of Deaf}

\author{
DOI: $10.46814 /$ lajdv2n5-004
}

Recebimento dos originais: 10/07/2020

Aceitação para publicação: 30/08/2020

\author{
Fernando Barcellos Razuck \\ Doutor em Educação pela Universidade de Brasília/Faculdade de Educação \\ Instituição: Instituto de Radioproteção e Dosimetria (IRD) \\ Endereço: Avenida Salvador Allende, 3773 - Barra da Tijuca, Rio de Janeiro - RJ, Brasil \\ E-mail: razuckdabrasilia@hotmail.com

\section{Renata Cardoso de Sá Ribeiro Razuck} \\ Doutora em Educação pela Universidade de Brasília/Faculdade de Educação \\ Instituição: Faculdade de Educação/Universidade Federal do Rio de Janeiro (UFRJ) \\ Endereço: Avenida Pasteur, 250, Urca, Rio de Janeiro - RJ, Brasil \\ E-mail: razuckrenata@gmail.com
}

\section{RESUMO}

Pode-se dizer que os museus e suas respectivas exposições museológicas têm um papel crucial no processo de inclusão social. No caso de exposições que envolvam temas ligado a questões científicas, podem também auxiliar na formação de conceitos na área. Dessa maneira, neste trabalho, estudou-se a visitação de um grupo de alunos surdos do Ensino Médio a uma exposição museológica científica, acompanhados por uma guia surda, da própria instituição, bem como por seus professores. Esta pesquisa teve como objetivo examinar de que maneira o conhecimento apresentado era compreendido pelos alunos, levando-se em consideração o impacto que um funcionário com as mesmas necessidades especiais, no caso um guia surdo, poderia causar no grupo de visitantes. Nesse sentido, entende-se que para facilitar o processo de inclusão de sujeitos com necessidades especiais, deve-se garantir a sua participação não só como espectadores, mas também como parte integrante do grupo de profissionais envolvidos no processo.

Palavras-Chave: Inclusão, Surdez, Popularização da Ciência.

\begin{abstract}
We can say that museums and their exhibitions in museums have a crucial role in the process of social inclusion. In the case of expositions involving issues related to science, it can also assist in the formation of concepts in the area. Thus, in this work, we studied the visitation of a group of high school deaf students at a science museum exhibition, accompanied by a guide deaf, that works ate the museum, as well as their teachers. This research aimed to examine how the knowledge presented was understood by the students, taking into account the impact that an employee with the same special needs, a guide deaf, could cause in the group of visitors. In this sense, it is understood that to provide the process of inclusion of individualswith special needs, should ensure their participation not only as spectators, but also as part of the group of professionals involved in the process.
\end{abstract}

Keywords: Inclusion, Deaf, Popularization of Science 


\title{
1 INTRODUÇÃO
}

De acordo com Instituto Brasileiro de Museus (IBRAM, 2010, p.8), é objetivo da Política Nacional de Museus

\begin{abstract}
Promover a valorização, a preservação e a fruição do patrimônio cultural brasileiro, considerado como um dos dispositivos de inclusão social e cidadania, por meio do desenvolvimento e da revitalização das instituições museológicas existentes e pelo fomento à criação de novos processos de produção e institucionalização de memórias constitutivas da diversidade social, étnica e cultural do país.
\end{abstract}

Nesse sentido, entende-se que os museus, com suas exposições museológicas, podem exercer um papel crucial para o processo de inclusão social. Segundo Ribeiro (2007), a partir da década de 1990, programas de inclusão sócio-educacional vêm ganhando visibilidade nos museus e centros de ciência e cultura, sensibilizando a sociedade sobre o assunto e estimulando iniciativas inclusivas em outros ambientes.

Além disso, os processos inclusivos também são de grande importância com relação aos eventos de cunho científico. Assim, uma das possibilidades que se abre vem a ser a correlação existente entre a inclusão e a Popularização da Ciência (PC).

Isto porque, de acordo com Tenório, Oliveira e Miranda (2009), a perspectiva de promover inclusão social, concebida como a participação direta da sociedade, vem buscando colaboração das práticas de PC, para além dos espaços da educação formal. Para isso, faz-se necessário que a escola adote políticas que promovam a diversidade, não apenas como a integração de alunos diferentes no espaço escolar regular, mas sim com práticas e metodologias que favoreçam a aprendizagem do saber científico para todos.

Assim, a correlação existente entre os processos inclusivos e a PC em museus se apresenta como uma grande possibilidade, conforme destacado pelo próprio IBRAM, segundo o qual, dentre as características e funções de um museu, cita no seu item III "a utilização do patrimônio cultural como recurso educacional, turístico e de inclusão social", mostrando assim a preocupação com a questão.

Especificamente com relação a alunos surdos, Marchesi e Martín (1995) defendem que a sua aprendizagem é diferenciada quando comparada a alunos ouvintes, devido ao que as possibilidades interativas de surdos acabam sendo menores.

Para Lacerda (2006) os alunos surdos não conseguem participar de eventos escolares discursivos fundamentais para a constituição plena do sujeito. Os eventos discursivos proporcionam o desenvolvimento de aspectos lingüísticos, sociais, afetivos, de identidade, entre outros. 
Assim, uma das possibilidades apresentadas para minimizar esse problema, é PC, pois, como defendido por alguns autores (MORAES, 2009; RAZUCK; SANTOS, 2017), esta possibilita a apropriação do discurso científico pelo cidadão, levando-o a se constituir como sujeito ao adquirir um domínio dos temas de Ciência e Tecnologia (C\&T), conduzindo-o a participar de forma ativa, do contexto em que vive. Logo, os museus de C\&T têm se destacado na implementação da PC visando à inclusão social dentro de novas perspectivas.

\section{O PROCESSO DE INCLUSÃO}

Cabe ressaltar aqui que entende-se o processo de inclusão como um processo social, conforme defendido por Vygotsky $(1997,2001)$, na qual a interação do aluno com o meio social, com seus pares, seria a responsável por acionar o processo de aprendizagem. Em seus estudos sobre a defectologia, Vygotsky (1997) defende que a deficiência não deve ser vista em função das suas dificuldades, mas sim de suas possibilidades.

Vygotsky (1997) critica a visão tradicional de educação que identifica o defeito como uma carência, um dano ou uma insuficiência, como algo que limita e restringe o desenvolvimento. O autor apresenta uma abordagem inovadora, passando a entender a deficiência como uma especificidade ou uma característica singular e diversa das pessoas. Posiciona-se então criticamente, sugerindo que qualquer característica individual que fuja daquilo que é mais comum, no ambiente social, tende a causar uma rejeição. Nessa análise, as deficiências são socialmente instituídas, aparecem como uma construção social, na medida em que não podem ser compreendidas na perspectiva da eclosão da diversidade e em uma possibilidade não anormal do desenvolvimento. Dessa forma, ressalta que a concepção da deficiência deve ser substituída por outra, que considere a dinâmica do desenvolvimento, partindo da posição fundamental de que o defeito implica em uma dupla influência. Ou seja, é uma insuficiência e atua diretamente como tal, criando prejuízos e obstáculos.

No entanto, para Vygotsky (1997), as deficiências servem também de estímulo ao desenvolvimento de caminhos de rodeio para a adaptação, ao desenvolvimento de funções substitutivas ou sobre-estruturadas, que tendem a compensar a insuficiência e a introduzir uma nova ordem em todo o sistema, introduzindo um novo equilíbrio.

Especificamente com relação aos surdos, Góes (1996) defende que eles apresentam, em sua maioria, desenvolvimento lento e incompleto do pensamento abstrato. Isto se deve ao fato de não possuem domínio consistente da linguagem, devido à pobreza de experiências envolvendo trocas comunicativas. Para a autora, na direção do enfoque histórico-cultural, o pensamento está 
subordinado à linguagem e, portanto, o desenvolvimento cultural só pode constituir-se na linguagem. Então, os surdos são prejudicados em seu desenvolvimento por serem introduzidos à LIBRAS e/ou à Língua Portuguesa muito tardiamente.

Segundo Skliar (1997), a surdez é comumente vista apenas pelo seu lado clínico terapêutico, na qual é entendida como uma impossibilidade. A partir do contato com outros sujeitos surdos atuantes na sociedade possibilita-se a visão sócio-antropológica da surdez segunda a qual esta é entendida como uma diferença na percepção sensorial, e não uma deficiência.

Nesse sentido, as visitações museológicas podem ser uma importante ferramenta para o processo não só de aprofundamento e desenvolvimento da língua de sinais - LIBRAS -, mas para favorecer o contato do surdo com outras linguagens e cidadãos surdos incluídos. Essas visitas são importantes para os surdos, pois lhes dão maior domínio de pensamento verbal, favorecendo não só a comunicação, mas também a estruturação do pensamento e a constituição da identidade.

\section{JUSTIFICATIVA}

De acordo com Ribeiro (2007), movimentos de caráter político e social têm dado sinais de uma nova cultura em museus, uma delas é a inclusiva. Os debates sobre os processos inclusivos têm sido estimulados, sendo inegável que a inclusão social das pessoas está na agenda do governo.

Políticos diretamente envolvidos com a C\&T tem se comprometido com essa agenda. Um exemplo disso é a implantação, no último governo, de um Departamento de Popularização e Difusão de Ciência e Tecnologia, no Ministério de Ciência e Tecnologia e Inovação (MCTI), que, a despeito de qualquer coincidência, está ligado à Secretaria de Ciência e Tecnologia para Inclusão Social.

No Brasil, e em outros países da América Latina, as novas políticas de inclusão acabaram por deflagrar reuniões científicas e didáticas para discussão de projetos e iniciativas de inclusão sócio-educacional emergentes de instituições públicas, privadas e de organizações nãogovernamentais. Ou seja, representam ações concretas, surgidas de um movimento coletivo de toda a sociedade.

A lei de acessibilidade foi promulgada há mais de 10 anos e diz:

O Poder Público promoverá a eliminação de barreiras na comunicação e estabelecerá mecanismos e alternativas técnicas que tornem acessíveis os sistemas de comunicação e sinalização às pessoas portadoras de deficiência sensorial e com dificuldade de comunicação, para garantir-lhes o direito de acesso à informação, à comunicação, ao trabalho, à educação, ao transporte, à cultura, ao esporte e aolazer. 
Dessa maneira, museus de ciências podem ser espaços com tremendo potencial educativo e, em especial, podem ser locais propícios no que se refere à inclusão, em especial a de pessoas com necessidades especiais.

No entanto, muitos museus ainda não estão preparados para atender visitantes com necessidades especiais. Há exceções e algumas instituições não tem poupado esforços para assegurar a acessibilidade de pessoas cegas e surdas às suas instalações e coleções. Existem museus organizados para receber surdos, diversos espaços estão contratando guias que sabem Libras, como também guias surdos para atender as escolas de surdos e visitantes surdos adultos. Essa ação é um incentivo para que os surdos participem mais desses espaços e sintam satisfação ao visitar museus.

Defende-se aqui que, para que os museus sejam de todos e para todos, é necessário que seus semelhantes façam parte do grupo de profissionais dessas instituições. Assim, ao identificar seus semelhantes trabalhando nessas instituições, os visitantes se sentem mais confortáveis durante a visitação, uma vez que têm a possibilidade de interagir por meio de sua língua, favorecendo com isso não só a participação, como a própria aprendizagem e a constituição da identidade surda, por exemplo. Essa participação deve ocorrer, portanto, desde o planejamento, organização até a execução das exposições (RAZUCK; RAZUCK, 2018).

\section{METODOLOGIA}

Neste trabalho analisou-se a visitação de um grupo de alunos surdos a uma exposição museológica do Centro Cultural Banco do Brasil (CCBB), em Brasília, acompanhados por seus professores e por uma guia da própria instituição, também surda.

A pesquisa teve como objetivo examinar como a presença de funcionários, com as mesmas necessidades especiais, contribui para o processo de engajamento, gerando assim um impacto ${ }^{1}$ no grupo.

\section{RESULTADOS}

A exposição visitada apresentava a mostra O Mundo Mágico de Escher, composta por cerca de 90 obras, entre gravuras originais e desenhos. Essa mostra foi escolhida pelo grupo de professores e pela intérprete que organizaram a visitação devido ao fato de apresentar variadas obras do autor, conhecido por suas surpreendentes gravuras (xilografias - imagens feitas em uma matriz de madeira - e litografias - matriz de pedra) e por suas relações matemáticas com a arte, envolvendo

\footnotetext{
${ }^{1}$ O termo "impacto" foi utilizado no sentido adotado por Porto (2008), que observou que o impacto causado por uma exposição museológica remete á motivação para aprender.
} 
questões como o infinito e perspectivas, representando construções com padrões geométricos que se transformam em novas formas, propiciando efeitos de ilusão de óptica.

Para isso acompanhou-se à exposição um grupo de dez alunos que cursavam os anos finais do Ensino Fundamental e sete alunos que cursavam o Ensino Médio. Suas idades variavam entre 11 e 22 anos. Essa visita foi planejada pela equipe de professores que, para isso, realizaram uma visitação prévia à exposição com o intuito de definir estratégias para um melhor aproveitamento pedagógico do passeio.

Assim, os professores decidiram iniciar a abordagem do tema da exposição em aulas prévias à visitação. Decidiram também fazer uma abordagem interdisciplinar, na qual os conteúdos de Matemática, História, Artes, Geografia, Ciências, Filosofia, Sociologia e Química puderam ser abordados de forma integrada.

Os dados coletados mostram que o grupo de alunos surdos visitantes demonstrou empolgação e interesse em apreciar as obras expostas. O interesse deles ficou ainda mais evidente ao perceberem que seriam guiados pela exposição por uma guia surda. A identificação imediata com a guia foi clara e a observação mostrou que os alunos passaram a participar ativamente e com interesse.

Demonstraram interesse em compreender como as gravuras e de saber como foram elaboradas, o que representavam, como estavam interligadas à realidade social da época, além da evidente curiosidade em saber como a guia havia aprendido sobre as obras e seus contextos culturais. Esse interesse do grupo cria possibilidades de conversação sobre formação acadêmica e cultural.

Os dados também mostram que os alunos se engajaram no processo educativo que fora planejado. Ao final da visita os alunos foram questionados sobre quais disciplinas escolares poderiam estar relacionadas à visita. $\mathrm{O}$ grupo foi bastante perspicaz ao conseguir identificar disciplinas e relacionar os pontos correlatos.

\section{CONSIDERAÇÕES FINAIS}

A análise dos dados coletados mostra que durante a visitação ao Centro Cultural, foi possível propiciar aos alunos surdos a possibilidade de ressignificação do seu entendimento da surdez. O grupo de surdos se sentiu convenientemente apoiado ao ter uma pessoa "igual" os guiando e, principalmente, "conversando" com eles e, claramente, por essa familiaridade foi possível a ocorrência de comunicação de duas vias. 
Percebe-se que a surdez durante a visitação foi esquecida, ou melhor, foi entendida como uma característica normal. Assim, a visitação a um espaço museológico quando guiada por portadores de necessidades especiais favorece o entendimento da surdez como um espaço de desconstrução das diferenças, em oposição à uma visão extremamente clínica.

Entende-se dessa maneira que a presença de profissionais, que são portadores de necessidades especiais, em instituições museológicas, possibilita aos visitantes a oportunidade de repensar seu posicionamento e papel social perante as diversidades, estimulando e garantindo a possibilidade de acesso e de engajamento de indivíduos com necessidades especiais, levando assim a uma real inclusão.

Dessa forma, entende-se a possibilidade de se explorar aspectos relacionados à Matemática e a outras esferas do saber, como Artes, Ciências, Química, Sociologia, História, Geografia e Filosofia, de forma lúdica e interativa.

Assim, a exploração que os professores fizeram das técnicas utilizadas pelo artista permitiu a correlação com conteúdos de Ciências e Química. A visualização das obras permitiu várias correlações com a Matemática.

Já as disciplinas de História, Geografia, Sociologia, Filosofia e Artes, foram contempladas com a correlação feita entre a época vivida pelo autor (segunda Guerra Mundial) e suas obras, nas quais a interpretação favorecia a reflexão sobre os fatos históricos, a sociedade e suas formas de expressão. Esses dados foram coletados por observação, gravação e posterior transcrição dos dados e entrevistas com os professores.

A guia teve o papel de apresentar a exposição, enquanto que os professores correlacionavam os conteúdos escolares com a visitação. A visitação ao Centro Cultural Banco do Brasil é extremamente facilitada, pela estrutura que é oferecida ao visitante, contando com transporte para os visitantes e com profissionais surdos graduados em Artes, que atuam como guias.

\section{REFERÊNCIAS}

IBRAM. Instituto Brasileiro de Museus. Definição de Museus. Disponibilizado em < http://www.ibram.gov.br/>. Acesso em 20 de agosto de 2010.

GÓES, M. C. R. de. Linguagem, Surdez e Educação. São Paulo: Editora Autores Associados, 1996.

LACERDA, C. B. F. A inclusão escolar de alunos surdos: o que dizem alunos, professores e intérpretes sobre esta experiência. Caderno CEDES, v. 26, n. 69. Campinas, 2006. 
MARCHESI, A.; MARTÍN, E. Comunicação, linguagem e pensamento das crianças surdas. In: COLL et al. (Orgs.) Desenvolvimento psicológico e educação: necessidades educativas especiais e aprendizagem escolar. Porto Alegre: Artes Médicas, 1995.

MORAES, R. Incursões no discurso da ciência: a popularização da ciência nos espaços dos Museus. Revista Virtual de Gestão de Iniciativas Sociais, v. 1, p. 1-14, 2009.

PORTO, F. de S. O impacto de exposições museológicas na motivação para aprender Ciências. 145 f. Dissertação (Mestrado Profissionalizante em Ensino de Ciências) - Universidade de Brasília, Brasília, 2008.

RAZUCK, F. B.; RAZUCK, R. C. S. R. Educação Matemática: a obra de Maurits Cornelis Escher como promotora de educação não foral em museus. Diálogos \& Ciência, v.1. p. 1-10, 2018.

RAZUCK, F. B.; SANTOS, W. L. P. A Popularização da Ciência na Semana Nacional de Ciência e Tecnologia: um estudo de caso, sob o enfoque CTS, da participação de uma instituição de pesquisa. Ensenanza de Las Ciencias, v. Extra, p. 1537-1542, 2017.

RIBEIRO, M. das G. Inclusão social em museus. In: X Reunión de la Red de Popularización de la Ciência y la Tecnologia em America Latina y el Caribe (RED POP

- UNESCO) y IV Taller “Ciência, Comunicación y Sociedad”. San José, Costa Rica, 2007.

SKLIAR, C. (org.) Educação \& exclusão - Abordagens Sócio-Antropológicas em Educação Especial. Porto Alegre: Editora Mediação, 1997.

TENÓRIO, L.M.F.; OLIVEIRA, L.R. MIRANDA, A.C. O Ensino de Ciências na educação de alunos surdos: a interface com a educação física. In: VII Encontro Nacional de Pesquisa em Ensino de Ciências (ENPEC). Anais do VII ENPEC. Florianópolis, 2009.

VYGOTSKY, L. S. Obras Escogidas. Volume V, Fundamentos de Defectologia, Madrid: Visor, 1997.

VYGOTSKY, L.S. Pensamento e Linguagem. 10a edição. Petrópolis: Vozes, 2001. 